\title{
Experience Predicting Construction-Site Noise
}

\author{
Michael A. Staiano
}

The practical aspects of predicting construction-site noise are examined: the implementation of the prediction process, including the use of suitable source-noise emission measurement standards, the identification of propagation factors, and the assumption of meteorological conditions. The application of a prediction procedure is compared with field measurements to verify accuracy and to establish appropriate design safety margins. To estimate the site sound levels from one or more noise sources, sound attenuation was considered due to four mechanismsspreading, atmospheric absorption. ground reflections ("ground interaction" $"$, and barrier shielding. Noise-source emissions were measured essentially at maximum noise-generation conditions for the equipment, based on the test procedures of both the Society of Automotive Engineers and the American National Standards Institute. Prediction accuracy was verified for eight sites with 19 total locations and conditions. When observed primary-machine sound levels were compared with the predictions, the mean error was $3 \mathrm{~dB}(\mathrm{~A})$ ). For group equipment operations and measurement-period sound levels. which are subject to source operating condition variation and mobile-equipment movement. the mean equivalent sound-level overprediction was approximately $6 \mathrm{~dB}(\mathrm{~A})$.

Empirical measurements and analytical predictions are alternative methods to quantify the noise emissions from a site. Each has advantages and disadvantages. Measurements have the advantages of quantifying actual, existing conditions (including those that are far too complex to be readily modeled in a prediction procedure) and of being more persuasive to laypeople than predictions. However, measurements have the disadvantages of being subject to sampling errors due to source variation and meteorological conditions the significance of which is often ignored) and of being relatively expensive to perform properly. On the other hand, predictions have the advantages of permitting quantification of noise sources and conditions that currently do not exist (e.g., the evaluation of noise controls) and of allowing the quantification of numerous locations relatively inexpensively. However, predictions have the disadvantages of being subject to enrors due to site-configuration simplification and activitydescription inaccuracies and of not being highly persuasive to laypeople. Measurements and predictions are best used to complement each other, with the empirical measurements verifying and calibrating the analytical predictions.

The prediction of noise from a facility or operation is often necessary as part of a plan-approval procedure to demonstrate compliance with (a) local noise ordinances, (b) an environmental assessment process for federally funded projects. or (c) the overall facility design to assure community acceptability of an industrial activity. Often these operations involve diesel-fuel-engined mobile equipment. Sites or operations requiring such predictions include transportation hubs

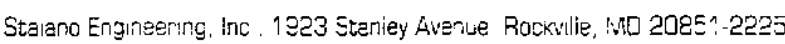

(e.g.. truck depots. bus terminals, and intermodal transfer facilities \}, mining operations (including stone quarries and other material extraction and processing facilities). and construction activities (including earth-moving equipment. temporary processing plants, pile driving. and blasting). Noise predictions for fixed facilities ofter must consider many component noise sources that are stationary in space and steady over time. Facilities involving site-based mobile noise sources are complicated because of the component noise sources' mobility, which causes site-noise emissions to fluctuate as a function of rapidly varyng distances and operating conditions. Noise from explosives blasting may contain a substantial low-frequency sound that is capable of propagating over very large distances under certain atmospheric conditions.

This paper examines the practical aspects of construction-site noise predictions using experience with construction, mining. and other mobile-equipment operations. Impulsive noise sources. such as blasting and pile driving are not considered. The review of the prediction process includes source identification and quantification. receptor selection. and propagation-path definition. Issues to be addressed include appropriate noise descriptors for various exposure siruations and prediction uncertainty. The implementation of the prediction process is examined to include the use of suitable source-noise emission-measurement standards. the identification of propagation factors, and the assumption of meteorological conditions. The application of a prediction procedure is compared to field measurements to verify accuracy and to establish appropriate design safety margins.

\section{SOUND-LEVEL DESCRIPTORS}

A variety of noise metrics have been defined for various purposes. Whereas all are correlated. some are easier to measure with simple instrumentation, some are better for predicting annoyance. and others more accurately describe certain noise sources. The most commonly used metrics are $\mathrm{A}$-weighted to correspond to human hearing sensitivity. The sound-level descriptor appropriate for site-noise prediction will be indicated by the criteria driving the requirement. Zoning regulations and local noise ordinances may be written in terms of $(a)$ average sound levels [also called equivalent sound levels $\left.\left(L_{* q}\right)\right]$ : (b) explacitly or implicitly as $N$ th percentile sound levels $\left(L,{ }^{\prime}-\right.$ that is, the sound level exceeded during $N$ percent of the measurement period (e.g., $L_{9 \mathrm{i}}$ is the sound level exceeded during 90 percent of the measurement period and is a measure of the relatively steady. low-level background noise, whereas $L_{1 ;}$ is the sound level exceeded during 10 percent of the measurement period and is a measure of brief, high-level noise events such as vehicle pass-bys): or (c) maximum sound levels $\left(L_{\text {max }}\right.$ ). Other limits may be expressed in terms of unweighted frequency spectra (e.g.. octave-band sound 
levels). However. most requirements are written in terms of overall A-weighted sound levels $\left(L_{A}\right)$, identified as maximum permissible or maximum allowable without elaboration. usually leaving the choice of metric and measuring procedure to the judgment (and competency) of the compliance officer.

When predicted sound levels are to be compared to land-use guidelines or used to estimate community response, the day-night average sound level $\left(L_{i r}\right)$ is most commonly employed. Day-right average sound levels usually are used to describe rail line and aircraft noise exposures, whereas I -h-duration equivalent sound levels or 10th percentile sound levels typically are used to describe highway noise. Noise from a site containing mobile equipment is best described in terms of equivalent or percentile sound levels (especially $L_{1 ;}$ or $L_{1}$ ). When a requirement is defined in terms of maximum pernissible or maximum allowable sound level, use of $L_{i}$, and not $L_{-2 \mathrm{x} x}$, is recommended to avoid undue infuences from very brief. atypical events and to limit the effect of measurement duration. The longer the measurement, the greater the maximum magnitude that is likely to be observed.

\section{PREDICTION ELEMENTS}

The noise prediction process is best understood by visualizing the three fundamental elements of a noise exposure-the noise source. the sound propagation path. and the sound receptor.

\section{Source Quantification}

The first step in predicting the noise exposure from a site is to idenify significant noise sources. Noise sources should be identified for inclusion in the prediction computation depending on their magnitude (particularly overall A-weighted sound level), their location onsite (to a lesser extent), and their duration of operation (depending on sound-level descriptor).

Once site-noise sources have been identified, their noise emissions must be quantified. Quantification may be in terms of sound-pressure levels at a reference distance or in terms of sound-power levels. It often is desirable to perform field-noise emission measurements of the actual equipment to be used. For diesel-fuel-powered. mobile equipment. the Sociery of Automotive Engineers (SAE) procedures are most useful. For pneumatic equipment, the Compressed Air and Gas Institute (CAGI) test code is available. For stationary equipment, the American National Standards Institute (ANSI) procedures. prepared by the Acoustical Society of America. provide useful guidance. Stationary noise-source emissions ideally are measured over an imaginary surface, as shown in Figure $1 a$ from ANSI S12.36-90 and then are averaged. The CAGI procedure (ANSI S5.1-71) is directed to the measurement of sound-pressure levels. SAE provides methods for obtaining either sound-pressure or sound-power levels. The SAE sound-power procedures are relatively complex and involve measurements over a hemispheric surface around the machine: thus, they are most suitable for equipment-manufacturer production testing and not for third-party field surveys. The ANSI guidelines are aimed at sound-power level quantification, are relatively complex. and are not source-specific. Note that

- Sound-power level quantifies the rate of sound-energy radistion from a source: thus. it is an intrinsic characteristic of the source.

- Sound-pressure level is the measure at a specific location of the sound disturbance caused by a source and depends on the envronment in which the source operates and on the distance from the source.
For relatively quick quantification of source-noise emissions, simplified techniques derived from industry and ANSI procedures can be used to support predictions with acceptable accuracy. For mobile equipment. SAE Standard J88 (S.AE J83) is a good starting point. SAE 388 has provisions for both stationary and mobile tests of engine-powered equipment. It provides for measurements with various operating conditions, as follows:

- Stationary tests, such as

- Maximum-govemed engine speed [high idle (HI) at no load],

- Low idle/maximum-governed speed/low idle (IMI), and

- High idle with cycling of major components (HIC) (e.g.. extension and retraction of a backhoe bucket); and

- Constant-speed moving test, a pass-by (PB) of a fixedmeasurement location with the machinery operated in an intermediate gear at maximum-governed speed.

For most requirements. stationary testing should be adequate for rubber-tired equipment such as wheel loaders and for primarily stationary machines sich as backhoes. However, for equipment with significant locomotive noise (e.g., crawler tractors or bulldozers). a moving-source pass-by test is preferable.

The SAE J88 procedure calls for slow-response, A-weighted measurement with a sound-level meter. For the HI condition, a single reading is to be made at each measurement location. For the IMI. $\mathrm{HIC}$, and PB test conditions, a minimum of three readings is required for each measurement location, plus additional readings if the measurement variability is too high. For the IMI. HIC, and PB tests. the reading consists of the maximum sound level during the test sequence (disregarding unrepresentative. short-duration sounds such as bucket impacts against its stops).

SAE stationary test measurements are made at a distance normal to the centers of the four major surfaces of a machine, excluding attachments (e.g. booms or buckets), as illustrated in Figure $1 b$.

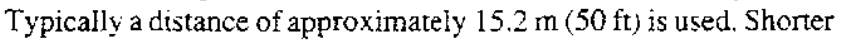
distances may be necessary if site-measurement conditions dictate (e.g., background noise or space constraints). Unlike sound-power methods. such as AVSI S12.36-90. which use an energy average. the reported SAE J88 sound level is the arithmetic average of the four measurement-location results.

In the evaluation for equipment noise emission levels, equipment sound-pressure levels first were measured close to individ. ual machines. The measurements were essentially at maximum noise-generation conditions for the equipment and were based on both the SAE J88 and ANSI S12.36-90 standard test procedures. $\mathrm{SAE}$ methods guided the measurement location selection and equipment test conditions. To compute sound-power level, the AVSI procedure was used (for the computation of the measurement envelope surface area). Because laypeople more easily understand the signifcance of a sound-pressure level at a specific distance than a soundpower level, the sound-power levels were used as an intermediate result from which to obtain equivalent sound-pressure levels. For the computations and subsequent reporting. equipment noise-emission levels were expressed in terms of sound-pressure level normalized to a 30.4-m (100-ft) reference distance.

\section{Propagation Attenuation}

The propagation path is the means by which the sound generated by a noise source reaches a sound receptor. Most propagation factors reduce the transmitted amplitude of the source-noise emissions. These 


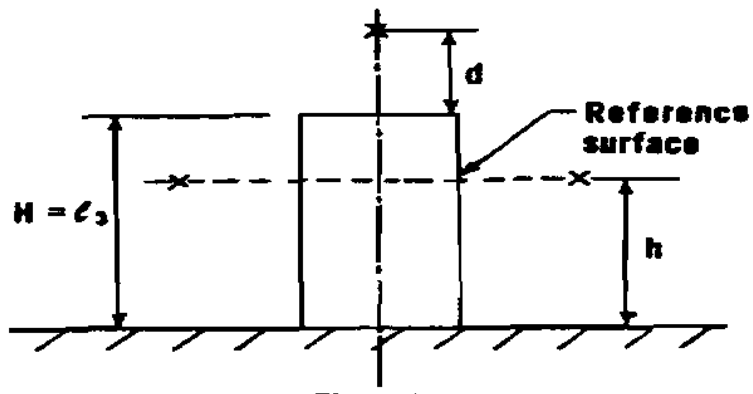

Elevation
For $H=2.5 m, h=(H+d) / 2$

The minimun helght of the micraphone above the refiecting plane shall be $0.15 \mathrm{~m}$ For $H=2.5 \mathrm{~m}$, take instead of $h$ two helghts:

$h_{1}=\{H+d\} / 2$ (tour key microphone positions as shown)

$h_{2}=(H+d)$ (Tour mierophone positions in the comers\}

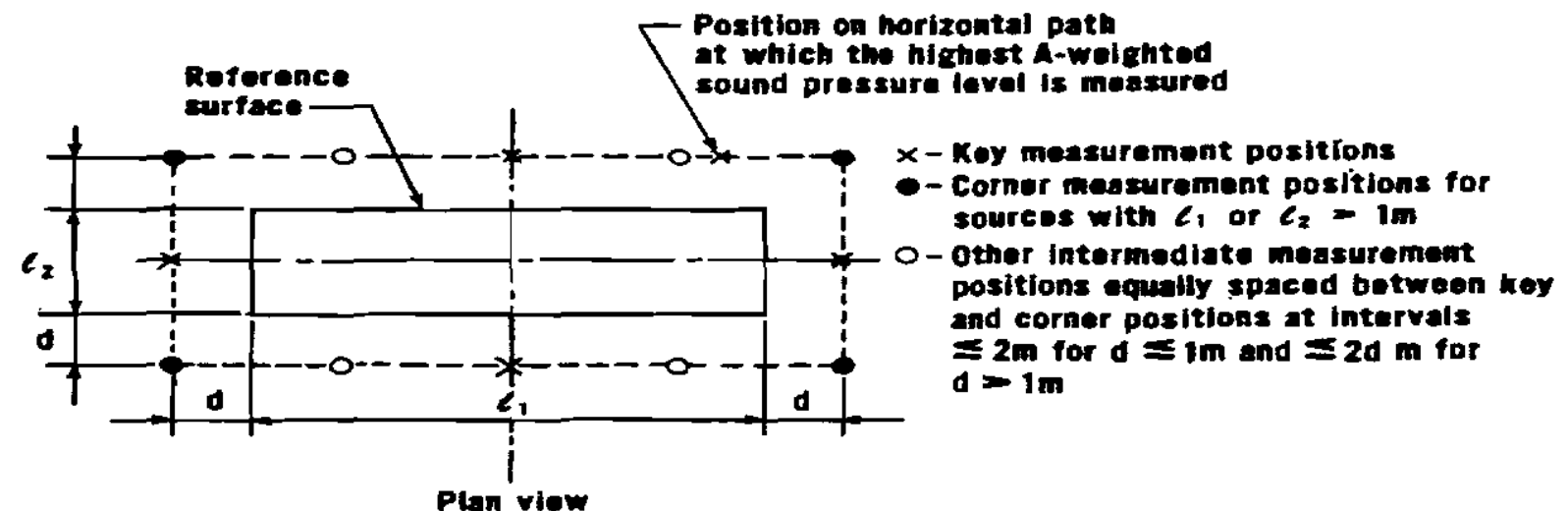

(a)
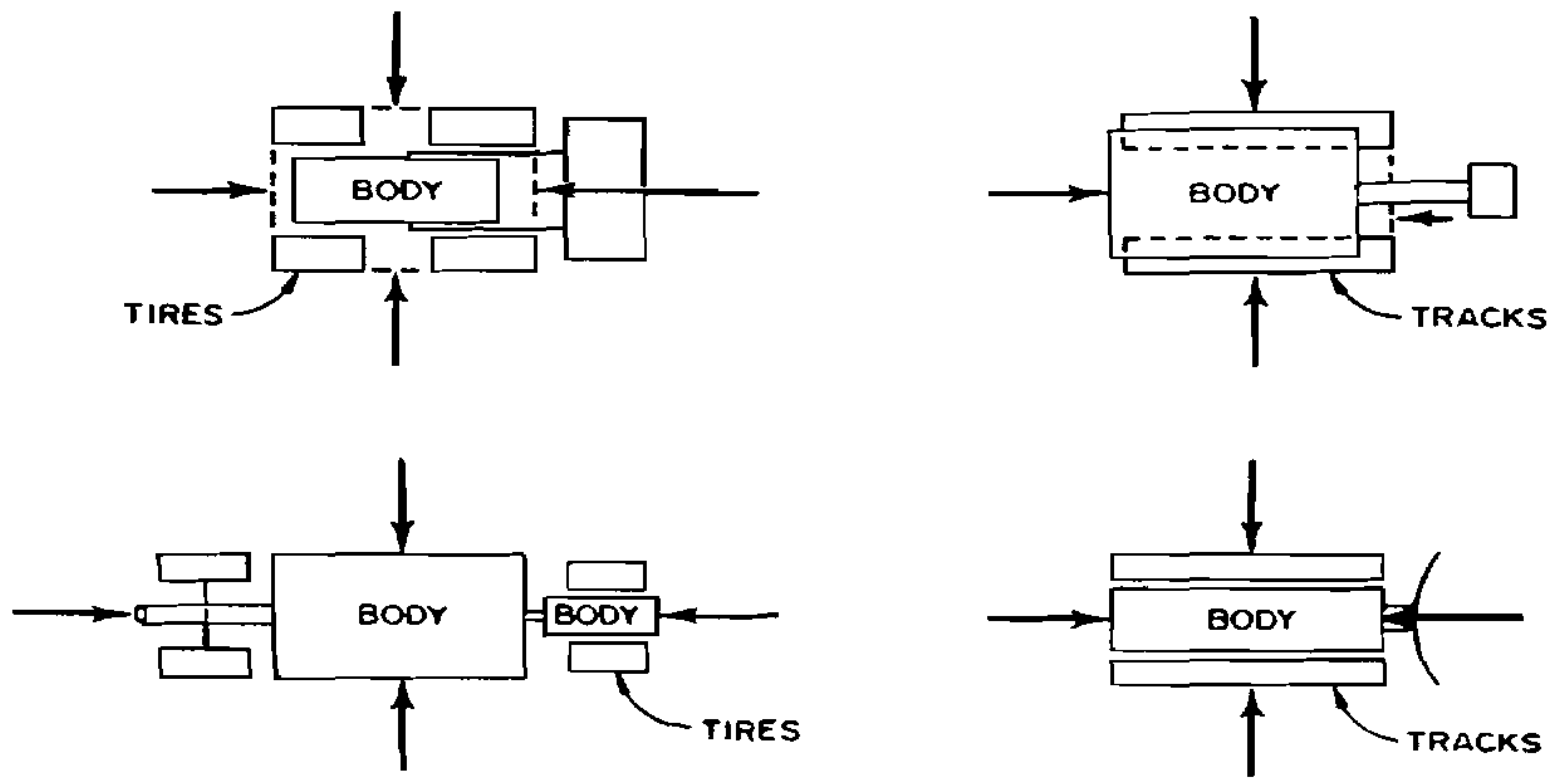

(b)

FIGURE 1 Recommended measurement locations: (a) ANSI S12.36, and (b) SAE JB8. 
include geometric spreading (divergence), atmospheric absorption. ground interaction. shielding (barrier effects), and scattering. Another propagation factor. sound path bending (due to atmospheric wind and temperature gradients with altitude). can either decrease or increase sound transmission. Many propagation factors-most notably, atmospheric absorption. ground interaction. and shielding - are functions of frequency. Thus, computation of their influence is best performed in frequency bands. However. because of other uncertainties arising from increasing frequency resolution. the use of frequency-band calculations may not yield significantly improved accuracy. For this reason, computations in terms of overall A-weighted sound levels provide satisfactory results (when hearing-related criteria are involved). Frequency-dependent propagation factors can be quantified using a representative frequency, even for broadband noise sources. For diesel-fuel-powered equipment and many other types of machinery. calculations at $500 \mathrm{~Hz}$ provide good results. For other sources with much different content or discrete frequency content. other frequencres may be more appropriate. (e.g., $1.000 \mathrm{~Hz}$ tor an electronic back-up alarm). For very long propagation distances or high-absorption weather conditions, however. frequency-band estimates should be made.

\section{Spreading}

Geometric divergence is almost always present and is a function of the source size relative to the source-receiver distance. For most noise sources, this attenuation can be computed simply by assuming that the source is a point or a line of noise. If a moving point source is to be evaluated in terms of a cumulative noise metric (e.g., $L_{\mathrm{eq}}$ or $L_{d n} 1$. its divergence characteristic will be that of a line source derined by the path of travel. Sound emanating from a point source of noise spreads spherically and decreases in intensity with distance, so that a reduction of $6 \mathrm{~dB}$ per doubling of distance from the source occurs. For example. a source that emits $85 \mathrm{~dB}(\mathrm{~A})$ at $30.4 \mathrm{~m}(100 \mathrm{ft})$ will cause $79 \mathrm{~dB}(\mathrm{~A})$ at $60.8 \mathrm{~m} .73 \mathrm{~dB}(\mathrm{~A})$ at $122 \mathrm{~m} .65 \mathrm{~dB}(\mathrm{~A})$ at $304 \mathrm{~m}$. and so forth.

\section{Atmospheric Absorption}

As sound propagates through the atmosphere, the vibration of the air molecules gradually dissipates the sound energy in proportion to the propagation distance (in addition to spreading losses). This attenuation depends strongly on frequency and relative humidity and. to a lesser exsent. on air temperature. According to ANSI SI .26-78, atmospheric absorption can range from a few tenths of a decibel per $300 \mathrm{~m}(1,000 \mathrm{ft})$ of propagation distance to more than $30 \mathrm{~dB}$ per $300 \mathrm{~m}$ ( $1,000 \mathrm{ft}$ ) of distance. Linless very specific circumstances are expected or the predicted results are to be compared to verification measurements, computation at a temperature/humidity condition corresponding to minimal sound attenuation is recommended. For most site-noise estimates, atmospheric absorption at $15^{\circ} \mathrm{C}\left(59^{\circ} \mathrm{F}\right)$ air temperature and 50 percent relative humidity are suggested.

\section{Ground interaction}

When a sound source or receiver is relatively close to the ground, significant interference can occur between the sound traveling directly from the source to the receiver and sound that is reflected from the ground. This interference depends on the frequency content of the sound, the refiection angie of the sound with the ground, and the penetrability of the sound into the ground (i.e.. whether the ground surface is hard or soft) (l). Hard surfaces, such as concrete, asphalt, or bodies of water, result in interference effects that are relatively insignificant. However, soft surfaces (i.e.. grass-covered ground or forest f(or) can cause significantly reduced sound levels at receiver locations.

Ground attenuation will be present. at least to some extent, if sound propagates over soft ground. It can be computed fairly rigorously if the reflection angle is known. However. for many outdoor propagation scenarios (e.g., the unfinished grading around construction sites ). the topography intervening the site and the receiver are highly irregular. Therefore. assumption of a smooth ground plane is the most reasonable, practical approximation without considerable complexity. For this purpose, a simple relationship that yields an attenuation increase of $1.5 \mathrm{~dB}$ (A) per doubling of distance or halving of source-receptor path height is adequate. A similar scheme is used in the obsolescent FHWA Traffic Noise Prediction Model re.g.. as implemented in the STAMNA computer program) (2).

\section{Shielding}

Topography also can provide shielding, resulting in noise barrier attenuation. Barrier attenuation is obtained when an obstruction is sufficiently tall. wide. and sound-impervious to require the sound from a noise source to bend around it to reach a receptor. The more bending required, the greater the attenuation obtained. For flat topography, a noise barrier is visualized easily as a wall perpendicular to the ground plane. When the terrain between the source and receiver is steeply sloping and irregular, the presence of shielding may not be readily obvious, and the specific terrain features that provide attenuation may be hard to identify. A reasonable method, which in most cases will underestimate the barrier attenuation, is to analyze only the highest point relative to a straight line between the source and receiver. A semi-empirical procedure was used for the computations (3). The caiculation incorporated an asymptotic. maximum barrier attenuation limit of $23 \mathrm{~dB}(\mathrm{~A})$ for topographic features and berms and $20 \mathrm{~dB}(\mathrm{~A})$ for walls.

When noise-control barriers are constructed. the apparent source height is increased (1.e.. the source appears to the receptor to be at the top of the barrier). Consequently, any ground attenuation present in the unshielded case is diminished. reducing the effective barrier attenuation. For engineering estimates, inclusion of only the maximum of the barrier or ground attenuation is siggested (as in the STAMINA procedure).

\section{Sound-Path Bending}

In a homogeneous medium. the natural sound propagation path is a straight line. Wind gradients can result in the bending of sound away from or down to the earth, depending on whether the sound propagation is upwind or downwind, respectively. Temperature gradients can cause sound to be bent away from the earth on clear days, increasing attenuation. whereas sound may be bent back to earth on clear nights, enhancing propagation. Wind and temperature gradient effects are highly variable. Unless prevailing downwind receptors or regular nighttime or early moming operations are anticipated, assuming a homogeneous atmosphere will usually provide conservative results (i.e.. overestimated sound levels). Straight-line propaga- 
tion, a good first approximation, rarely will be exactly representative but will be conservative for most daytime temperature gradients and for upwind or crosswind propagation. However, it will result in underestimates of sound for downwind or for some nighttime and earlymoming conditions (e.g. temperature inversions). If necessary, the likelihood of downwind effects can be evaluated probabilistically from wind-rose data available at most aviation facilities and airpollution monitoring stations.

\section{Focusing}

Wind and temperature gradients that change as a function of altitude not only can bend sound back down to earth but also can focus it into a small area, resulting in much higher sound levels than normaliy would be experienced and producing audible noise several miles from a source site. It usually is significant only for high-intensity, low-frequency noise sources such as explosives blasting. The highly irregular atmospheric gradients that produce focusing generally can be ignored for noise predictions of most construction-equipment noise sources.

\section{Scattering}

A widespread public perception exists that sound propagating through a wooded area is greatly attenuated. Tree rrunks, branches, and leaves can produce some scattering of sound and can reduce the amount of noise reaching a receiver. However, this factor is relatively insignificant. In most situations, it is best ignored. perhaps yielding slightly conservative results. Of greater importance is the influence of the tree roots loosening the ground. This enhances ground attenuation at low frequencies and is quantified by the ground-interaction factor. For very large propagation distances. atmospheric turbulence can provide significant scattering, but this also can be ignored for most groundbased noise sources. Row's of relatively small buildings. such as in a suburban residential development. also may provide scattering or shielding benefits. Attenuation can be estimated depending on the density and number of rows of houses. However, ignoring such attenuation is suggested unless the density or depth of houses is considerable or the evaluation location is very close to a specific structure (warranting a barrier-attenuation estimate for that structure).

\section{Receiver Sound Levels}

To estimate the site sound levels. sound attenuation was considered due to four mechanisms-spreading, atmospheric absorption, ground reflections, and bartiers. The site sound levels for each source type and source location were calculated as

$L_{A r}=L_{\mathrm{i}:}-A_{\mathrm{s}}-A_{\lrcorner}-\max \left(A_{\kappa}, A_{\mathrm{r}}\right)$

where

$L_{A r}$ is the receptor-jocation $A$-weighted sound-pressure level:

$L_{A}$ is the source-noise emission quantified by its sound-pressure level at a reference distance, usually $30.4 \mathrm{~m}$ (100 ft);

$A_{c}$ is the geometric divergence attenuation;

$A_{a}$ is the atmospheric attenuation for a reference frequency, $F_{\mathrm{KEF}}$ :

$A_{g}$ is the ground attenuation; and

$A_{b}$ is the barrier-shielding atteruation for a reference frequency, $F_{\text {REF }}$.
For the computation of A-weighted sound levels, the absorption rates and barrier attenuation are determined for a reference frequency, $F_{\mathrm{REF}}$, as representative of the overall A-weighted frequency content of the equipment-noise sources. At each receptor location, all sound levels are computed for each noise source with significant contribution to the receptor, combined-equipment, operation noise exposure. The total receiver sound level is found by the logarithmic "decibel addition" of the receiver sound levels of the individual sources.

\section{Receptor Characterization}

Most laypeople are accustomed to seeing noise exposures depicted in terms of equal-noise-exposure contours, such as those prepared for airports. Contours are useful when exposures to relatively large geographic areas must be evaluated. However, for most other noise sources, the burden of computing sufficient points to describe a contour line and the eror entailed in interpolating between prediction locations, or that interpolation error alone, provide little benefit versus selected discrete locations around a noise-generating site. Points may be selected as noise-sensitive locations with the criteria for their inclusion being who (or what) will be affected and how. Closely grouped noise-receptor locations can be evaluated at a single representative geographic point. Receptor locations should be selected to consider the proximity to the source site and component activities. the presence or absence of topographic or man-made shielding features. and the various compass points around the facility. Note that for sites with perimeter noise barriers. a property-line evaluation location may have a noise exposure lower than that experienced in the interior of the sound-receiving property located farther from the norse sources. This results from barrier attenuation decreasing more rapidly than distance attenuation increases and is a function of the source-barrier-receptor geometry.

\section{SITE-NOISE PREDICTION EXAMPLES}

Measurements were performed at receptor locations for the machines working together in normal production activities; then receptor predictions were made based on the close-in equipment measurements. Mobile noise sources were assumed at specific locations representative of their realistic maximum noise contribution to the evaluated receptor (essentially a "snapshot" of the site in its noisiest configuration. The orientation and directional sound radiation characteristics of the noise sources were ignored ii.e., the sources were assumed omnidirectional). This is a poor, but worst-case. assumption for sources such as electronic backup alarms.

Examples of the application of these procedures follow for the loading and hauling activines at a sand and gravel site and for the filling and grading activities at an ashfill operation.

\section{Sand and Gravel Extraction Site}

\section{Measured Individual Equipment Emissions}

Sound-ievel measurements were performed on each of the four sides of the mobile equipment, $15.2 \mathrm{~m}(50 \mathrm{ft}$ ) from the machine surfaces. The tests were performed on a portion of the site in a flat area where background noise was much less than the equipment sound levels. Four types of mobile equipment used for loading and hauling were evaluated-wheel-type loader. backhoe, track-type dozer, 
and scraper. For these sources, sound levels were determined with equipment operation per the pass-by and machine-stationasy operating modes-HI. I.MI, and HIC. Measurements were performed in the various operating modes to allow the selection of the most appropriate test condition for quantifying the equipment emissions. Test condition maximum sound level $\left(L_{\text {max }}\right)$ and equivalent sound level $\left(L_{\text {eq }}\right.$ ) both were recorded.

Sound-level measurements were performed using a sound-ievel meter set for "slow" time weighting and " $\mathrm{A}$ " frequency weighting, and they were programmed for integrating sound-level measurement. The operating-cycle or 30 -s-duration equivalent $\left(L_{-4}\right)$ and maximum $\left(L_{n+x}\right)$ sound levels were recorded. Table 1 is an example of the test results for the bulldozer.

The results of the measurements for the four machines at the four operating conditions are given in Table 2 , with both arithmetic averaging per SAE and energy averaging per ANSI provided. For the stationary tests, the greacly increased complexity of the IMI and HIC tests did not appear to yield significantly different results from the $\mathrm{HI}$ test: energy averaging was chosen to compute the spatial average because it is consistent with sound-power procedures. For the dozer, the energy-averaged, pass-by resutts in terms of $L_{\max }$ were selected as most appropriate. The preferred parameters are designated by bold type in Table 2.

The normalized equipment-noise emission levels in terms of both sound-power and sound-pressure levels are given in Table 3. Normalized sound-pressure levels for backup alarms and pass-bys were obtained by considering only geometric divergence. The maximum sound level was selected to describe the backup alarms.

\section{Predicted Site Sound Levels}

The sound-emission levels for the equipment, $L_{\dot{n}, \text {, }}$ at the reference distance are the bold-type "100-FT. [30-M] NORM. SPL" in Table 3. The results of the predictions. $L_{i r}$, at a receptor location are given in Tabie 4.

\section{Ashfill Operation}

\section{Measured individual Equipment Emissions}

Sound-level measurements were performed at an ashfill on each of the four sides of the mobile equipment. $15.2 \mathrm{~m}$ ( $50 \mathrm{ft}$ ) from the machine

TABLE 1 Equipment Test Data-Dozer at Sand and Gravei Site

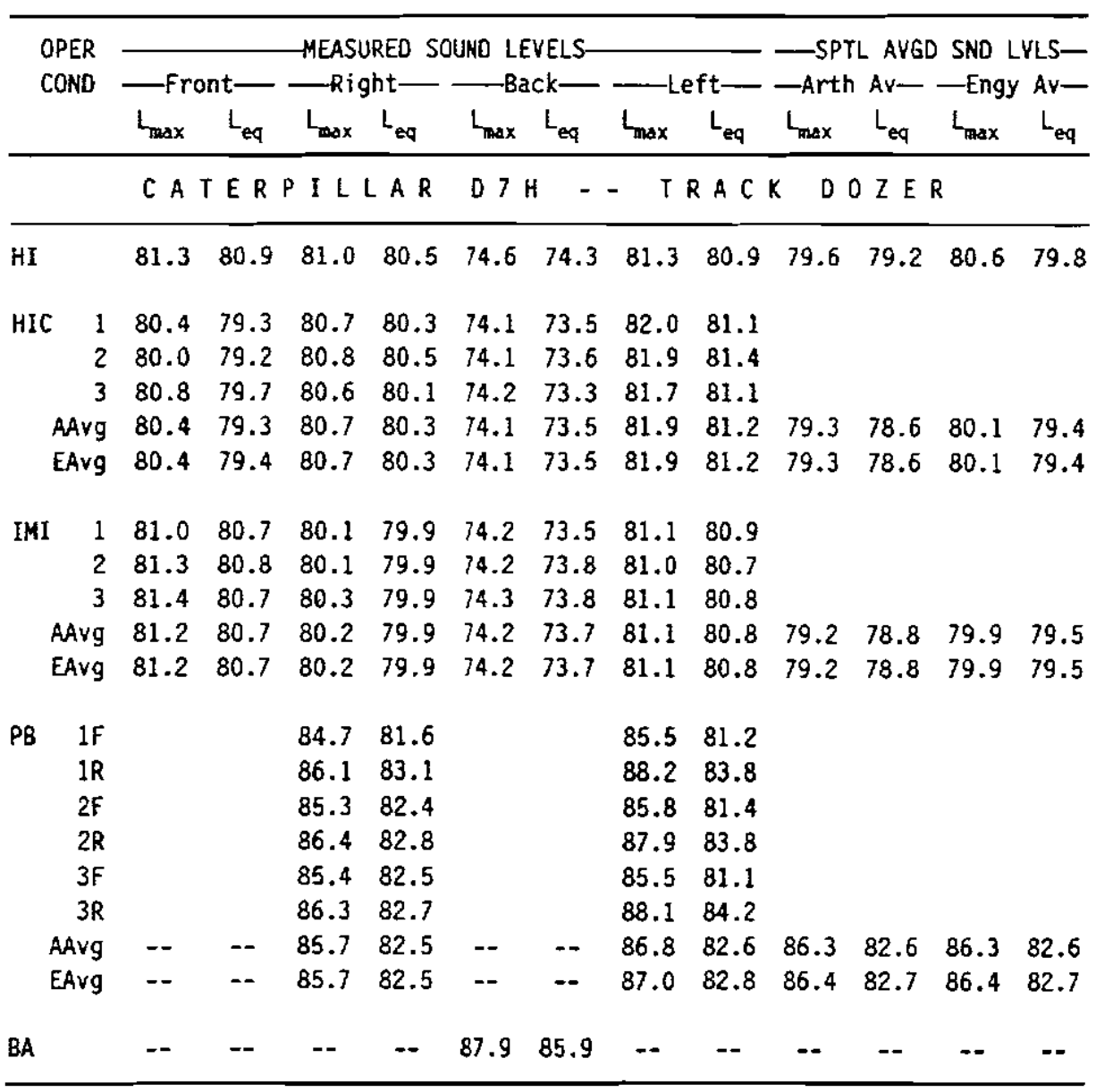

Fest conditions: HI, high idle

HIC, high idle with component cycling

IMI, low idle/maximurn governed speed/low idle

PB, constant-speed pass by

$B R$, back-up alarm 
TABLE 2 Equipment Test Data Summary-Sand and Gravel Site, Measured $15.2 \mathrm{~m}$ [50 $\mathrm{f}$ ) from Machine Surfaces

\begin{tabular}{|c|c|c|c|c|c|c|}
\hline MACHINE & METRIC & $\begin{array}{l}\text { AVER- } \\
\text { AGING }\end{array}$ & $\begin{array}{c}-4-\text { SIDE } \\
\mathrm{HI}\end{array}$ & $\begin{array}{c}\text { AVG } O \\
\text { HIC }\end{array}$ & $\begin{array}{r}\text { RATING } \\
\text { IMI }\end{array}$ & $\operatorname{COND} \cdot \frac{}{\mathrm{PB}^{*}}$ \\
\hline \multirow[t]{4}{*}{ LOADER } & & Arith & 79.3 & 79.4 & 77.9 & -- \\
\hline & & Enrgy & 80.7 & 80.2 & 79.1 & -- \\
\hline & & Arith & 79.8 & 80.3 & 78.9 & -- \\
\hline & & Enrgy & 81.3 & 80.9 & 80.3 & -- \\
\hline \multirow[t]{4}{*}{ BACKHOE } & & Arith & 73.2 & 75.1 & 72.9 & -- \\
\hline & & Enrgy & 74.0 & 75.6 & 73.9 & -- \\
\hline & & Arith & 73.8 & 76.6 & 73.7 & - \\
\hline & & Enrgy & 74.5 & 77.0 & 74.5 & -- \\
\hline \multirow[t]{4}{*}{ SCRAPER } & & Arith & 76.0 & 78.9 & 75.9 & - \\
\hline & & Enrgy & 78.5 & 80.0 & 78.3 & - \\
\hline & & Arith & 76.7 & 82.1 & 76.9 & -. \\
\hline & & Enrgy & 79.1 & 82.5 & 79.1 & -- \\
\hline \multirow[t]{4}{*}{ DOZER } & 1 & Arith & 79.2 & 78.6 & 78.8 & 82.6 \\
\hline & & Enrgy & 79.8 & 79.4 & 79.5 & 82.6 \\
\hline & $L_{\max }$ & Arith & 79.6 & 79.3 & 79.2 & 86.3 \\
\hline & $L_{\max }$ & Enrgy & 80.6 & 80.1 & 79.9 & 86.3 \\
\hline
\end{tabular}

"2-side average

TABLE 3 Sand and Gravel Site: Equipment Noise Emission Leveis

\begin{tabular}{|c|c|c|c|c|c|c|c|c|c|c|c|c|c|}
\hline \multirow[t]{2}{*}{ SOURCE } & \multirow{2}{*}{$\begin{array}{l}\text { OP. } \\
\text { CONO. }\end{array}$} & \multirow{2}{*}{$\begin{array}{c}\text { MEASMT. } \\
\text { OISTANCE } \\
(\mathrm{ft})\end{array}$} & \multicolumn{5}{|c|}{ MEASUREO SOUNO LEVELS (dBA)- - - } & \multicolumn{2}{|c|}{ SRC. DIMENS. } & \multirow{2}{*}{$\begin{array}{l}(f t) \\
\text { Hght }\end{array}$} & \multirow{2}{*}{$\begin{array}{l}\text { MEASMT. } \\
\text { SURFACE } \\
\text { AREA }\left(\mathrm{ft}^{2}\right)\end{array}$} & \multirow{2}{*}{$\begin{array}{c}\text { SOURCE } \\
\text { PUL } \\
\text { (OBA) }\end{array}$} & \multirow{2}{*}{$\begin{array}{c}\text { 100-FT } \\
\text { NOPM. } \\
\text { SPL(dBA) }\end{array}$} \\
\hline & & & Front & Right & Back & Left & $\begin{array}{c}\text { SPATIAL } \\
\text { AVG }\end{array}$ & Lgth & Wdth & & & & \\
\hline LOADER & $\mathrm{J} 88 / \mathrm{HI}$ & 50 & 71.9 & 81.4 & 82.2 & 81.7 & 80.7 & 22.0 & 10.1 & 11.4 & 41938 & 116.6 & 78.9 \\
\hline - -back-up alarm & $x$ & 50 & & & 89.4 & & & & & 5.0 & & & 83.4 \\
\hline --back-up alarm & $L_{\text {eq }}$ & so & & & 87.0 & & & & & & & & 81.0 \\
\hline BACXHOE & $\mathrm{J} 88 / \mathrm{HI}$ & 50 & 69.0 & 76.6 & 74.4 & 72.7 & 74.0 & 19.3 & 11.7 & 9.5 & 40795 & 109.8 & 72.1 \\
\hline SCRAPER & $\mathrm{J} 88 / \mathrm{HI}$ & 50 & 81.5 & 76.9 & 65.6 & 77.8 & 78.5 & 40.7 & 11.7 & 11.7 & 46829 & 114.9 & 77.2 \\
\hline -back-up alarm & $L_{\max }$ & 25 & & & 46.4 & & & & & 2.0 & & & 34.4 \\
\hline DOZER & $J 88 / P B$ & 50 & & 85.7 & & 86.8 & 86.3 & & 8.6 & & & & 80.3 \\
\hline --back-up alarm & $L_{\max }$ & 50 & & & 87.9 & & & & & & & & 81.9 \\
\hline --back-up alarm & $\mathrm{L}_{\text {eq }}$ & 50 & & & 85.9 & & & & & & & & 79.9 \\
\hline
\end{tabular}


TABLE 4 Sand and Gravel Site: Predicted Sound Levels, Rounded to Nearest Decibel

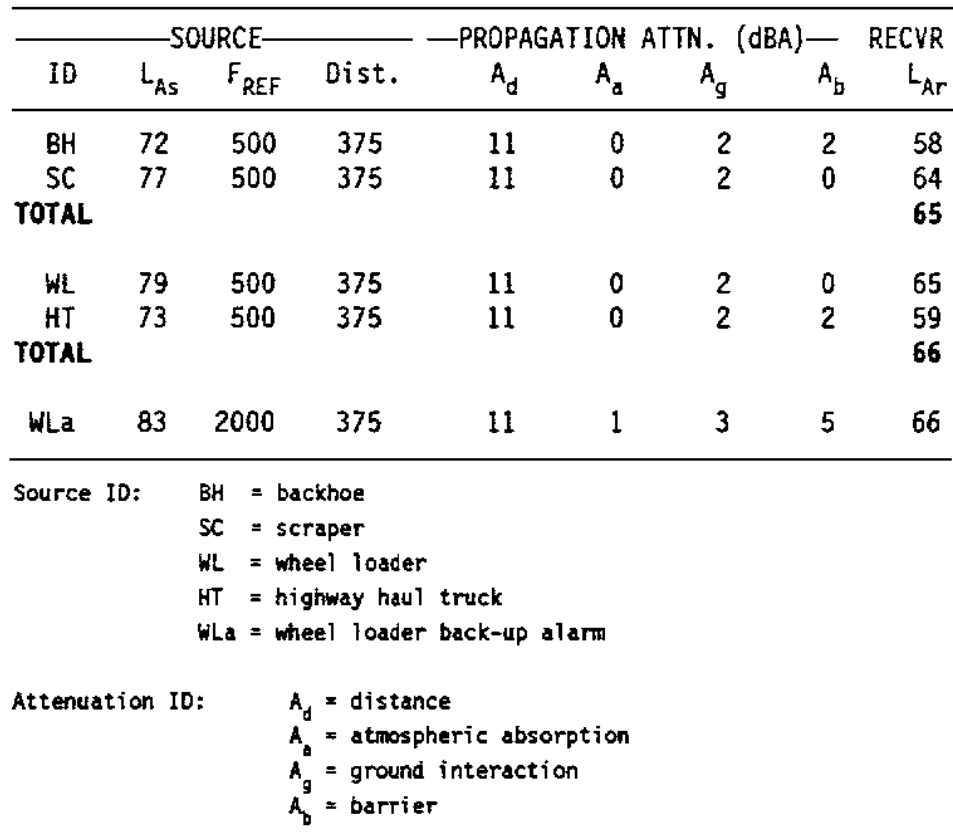

surfaces. The tests were performed on a portion of the site in a flat area where background noise was much less than the equipment sound levels. Four types of mobile equipment, used for hauling and grading, were evaluated-track-type loader. track-type dozer, vibratory roller, and highway-type, rear-dump haul truck (with bed vibrator). For these sources, sound levels were determined with equipment operation per the pass-by and the following machine-stationary operating modes-mI and HIC. The sound-level measurements were performed using the same instrumentation and procedures as at the sand and gravel pit.

Special tests were performed on two of the machines. The vibratory roller was tested with and without the vibrator engaged. The dump truck was tested for engine noise at high idle with lifted dump bed and for the raised bed with bed-mounted vibrator engaged. The test results are given in Table 5. Note that with the bed-mounted vibrator, the height of the dump truck becomes the height with the raised bed.

TABLE 5 Ashfill Operation: Equipment-Noise Emission Levels

\begin{tabular}{|c|c|c|c|c|c|c|c|c|c|c|c|c|c|}
\hline SOURCE & $\begin{array}{c}\text { OP. } \\
\text { COND. }\end{array}$ & $\begin{array}{l}\text { MEASMT. } \\
\text { DISTANCE } \\
\text { (ft) }\end{array}$ & Front & $\begin{array}{l}\text { IEASURED } \\
\text { Right }\end{array}$ & $\begin{array}{l}\text { SOLND LEV } \\
\text { Back }\end{array}$ & $\begin{array}{l}\text { LS ( } D B A) \\
\text { Left }\end{array}$ & $\begin{array}{c}\text { SPATIAL } \\
\text { AVG }\end{array}$ & $\begin{array}{l}\text { SRC. D } \\
\text { Lgth }\end{array}$ & $\begin{array}{l}\text { IMENS. } \\
\text { Wdth }\end{array}$ & $\begin{array}{l}\text { (ft) } \\
\text { Hght }\end{array}$ & $\begin{array}{l}\text { MEASMT. } \\
\text { SURFACE } \\
\text { AREA }\left(\mathrm{ft}^{2}\right)\end{array}$ & $\begin{array}{c}\text { SOURCE } \\
\text { PUL } \\
\text { (dBA) }\end{array}$ & $\begin{array}{c}100-F T \\
\text { NORM. } \\
\text { SPL(dBA) }\end{array}$ \\
\hline DOZER & $\mathrm{JBB} / \mathrm{PB}$ & 50 & & 79.2 & & 79.5 & 79.4 & 15.0 & 9.8 & 12.2 & 40565 & 115.1 & 77.5 \\
\hline --back-up alarm & $L_{\max }$ & 50 & & & 82.8 & & & & & & & & 76.8 \\
\hline DUAP TRUCK & J88/HI & 50 & 72.9 & 70.7 & 58.2 & 71.9 & 70.7 & 24.5 & 8.1 & 8.5 & 40669 & 106.5 & 68.8 \\
\hline --bed lift & & 50 & 65.8 & 65.5 & 57.1 & 65.0 & 64.4 & 24.5 & 8.1 & 8.5 & 40669 & 100.2 & 62.5 \\
\hline --bed vibrator & $L_{e q}$ & 50 & 95.0 & 93.9 & 92.8 & 94.9 & 94.2 & 24.5 & 8.1 & 17.1 & 44681 & 130.4 & 92.8 \\
\hline --back-up alarm & $L_{\max }$ & 50 & & & 86.1 & & & & & & & & 80.1 \\
\hline VIBRATORY ROLLER & $\mathrm{J} 88 / \mathrm{HI}$ & 50 & 65.4 & 77.0 & 79.7 & 77.4 & 77.0 & 17.3 & 7.6 & 9.5 & 39417 & 112.7 & 75.0 \\
\hline --w/vibrator & $388 / \mathrm{KI}$ & 50 & 69.9 & 77.4 & 79.4 & 77.6 & 77.2 & 17.3 & 7.6 & 9.5 & 39417 & 112.8 & 75.2 \\
\hline --back-up alarm & $\mathrm{L}_{\max }$ & 50 & & & 92.6 & & & & & 3.0 & & & 86.6 \\
\hline TRACK LOADER & $\mathrm{J} 88 / \mathrm{HI}$ & 50 & 66.9 & 70.1 & 75.6 & 71.1 & 72.1 & 15.0 & 8.0 & 10.8 & 39552 & 107.7 & 70.1 \\
\hline --back-up alarm & $L_{\max }$ & 50 & & & 79.7 & & & & & & & & 73.7 \\
\hline
\end{tabular}


TABLE 6 Ashfill Operation: Predicted Sound Levels, Rounded to Nearest Decibel

\begin{tabular}{|c|c|c|c|c|c|c|c|c|}
\hline & & $-\mathrm{SC}$ & & & PROPAGATION & ATTM. & $(d B A)$ & RECVR \\
\hline I0 & $N$ & $L_{\text {As }}$ & $F_{\text {REF }}$ & Dist. & $A_{d}$ & $A_{\mathrm{a}}$ & $A_{g}$ & $L_{A r}$ \\
\hline TD & 1 & 78 & 500 & 440 & 13 & 0 & 3 & 61 \\
\hline HT & 2 & 69 & 500 & 440 & 13 & 0 & 4 & 55 \\
\hline HTV & 1 & 93 & 500 & 440 & 13 & 0 & 2 & 77 \\
\hline VR & 1 & 75 & 500 & 440 & 13 & 0 & 3 & 59 \\
\hline VRa & 1 & 87 & 2000 & 440 & 13 & 1 & 5 & 68 \\
\hline TL & 1 & 70 & 500 & 440 & 13 & 0 & 3 & 54 \\
\hline TOTAL & & & & & & & & 78 \\
\hline
\end{tabular}

Source 1D: $\quad$ TD $=$ track dozer

HT = haul truck

HTY = haul truck vibrator

$V R=$ vibratory roller

$V R a=$ vibratory roller back-up al arm

$T L=$ track loader

Attenuation I0: $\quad R_{d}=$ distance

$A_{c}=$ atmospheric absorption

$A_{g}=$ ground interaction

\section{Predicted Site Sound Levels}

The sound-emission levels for the equipment at the reference distance are the bold-type "100-FT [30-M] NORM. SPL" in Table 5. To estimate the site sound levels, sound attenuation was considered due to three mechanisms-distance. atmospheric absorption. and ground interaction. No noise barriers were present. The results of the predictions are given in Table 6.

\section{OVERALL PREDICTION EXPERIENCE}

The location-specific prediction procedure that was just described has been applied to a number of sites. Prediction accuracy has been verified in cases in which adequate receiver noise exposure measurements are available. Eight sites, with 19 total locations and conditions [spanning distances of 61 to $640 \mathrm{~m}$ (200 to $2.100 \mathrm{ft}$ )]. were considered. The measured sampling-period sound levels were compared to the predicted sound levels, shown in Figures 2 and 3 as a function of source-receptor distance.

The predictions each included two to seven noise sources and were based on equipment-noise emission tests with steady-source operation (e.g.. diesel-fuel equipment at high idle). In actual operations, machinery loading varies considerably. such as a heavy truck operating in stop-and-go traffic. Furthermore, other noise-generation mechanisms. not represented in the equipment emission testing. may occur randomly. For example, the impact of a bucket in its linkage backup alarm noise, and the impact of material dumped onto a haul-truck bed all are absent from the noise-emission test of a wheel loader, but they are present in production operations. However. for any given activity. a numerical relationship can be computed between the observed primary-machine fluctuating sound levels and the equipment-ensemble long-tem sound-level statistics. The primary machine is defined as the individual item (or items) of equipment that operates most consistently and is likely to have the greatest influence on group-equipment operation sound levels (e.g., the wheel loader or backhoe in an earth-moving operation).

\section{Primary-Machine Sound Levels}

Figure 2 compares predictions to observed primary-machine sound levels $\left(L_{\text {A.pm }}\right)$. When the primary-machine field verification sound levels were compared to the predictions, the mean error was $3 \mathrm{~dB}(\mathrm{~A})$ (when rounded to the nearest decibel), with a $6 \mathrm{~dB}(\mathrm{~A})$ standard deviation in 19 measurement-prediction pairs. These results are summarized in Table 7 .

\section{Equipment-Ensemble Sound Levels}

Figures $3 a$ and $3 b$ compare predictions to the group equipment operations/measurement period sound levels ( $L_{\mathrm{sq}}$ and $L$ in 16 and 13 comparisons, respectively). The mean equivalent sound tevel overprediction was about $6 \mathrm{~dB}(\mathrm{~A})$ (when rounded to the nearest decibel). For the 50th. 10th. and 1st percentile sound levels. the mean "errors" were about $8 \mathrm{~dB}(\mathrm{~A}) .4 \mathrm{~dB}(\mathrm{~A})$, and $-1 \mathrm{~dB}(\mathrm{~A})$. respectively [with standard deviations of 4 to $6 \mathrm{~dB}(\mathrm{~A})$ ].

\section{Sound-Level Descriptor Adjustments}

The measurement database described earlier permitted the estimation of numerical relationships for the different noise descriptors. During a test period. sound levels observed with primary machine operation were noted. The highest of these sound levels (presumably at fullthrottle operation for diesel-fuel-powered mobile equipment) then were compared to the measurement-period equivalent and percentile sound levels. Depending on the descriptor. 13 to 16 comparisons were made, producing the mean "Descriptor Adjustments" given in Table 7. These adjustments are such that, for example, the groupequipment operation equivalent sound level is $4.5 \mathrm{~dB}$ (A) numerically lower than the observed primary-machine sound level i i.e., $L_{\mathrm{eq}}=L_{\mathrm{Apr}}$ -5 ; similarly. $L_{:}: L_{A p m}-2$. etc. . The descriptor adjustment explains much of the prediction "error." 


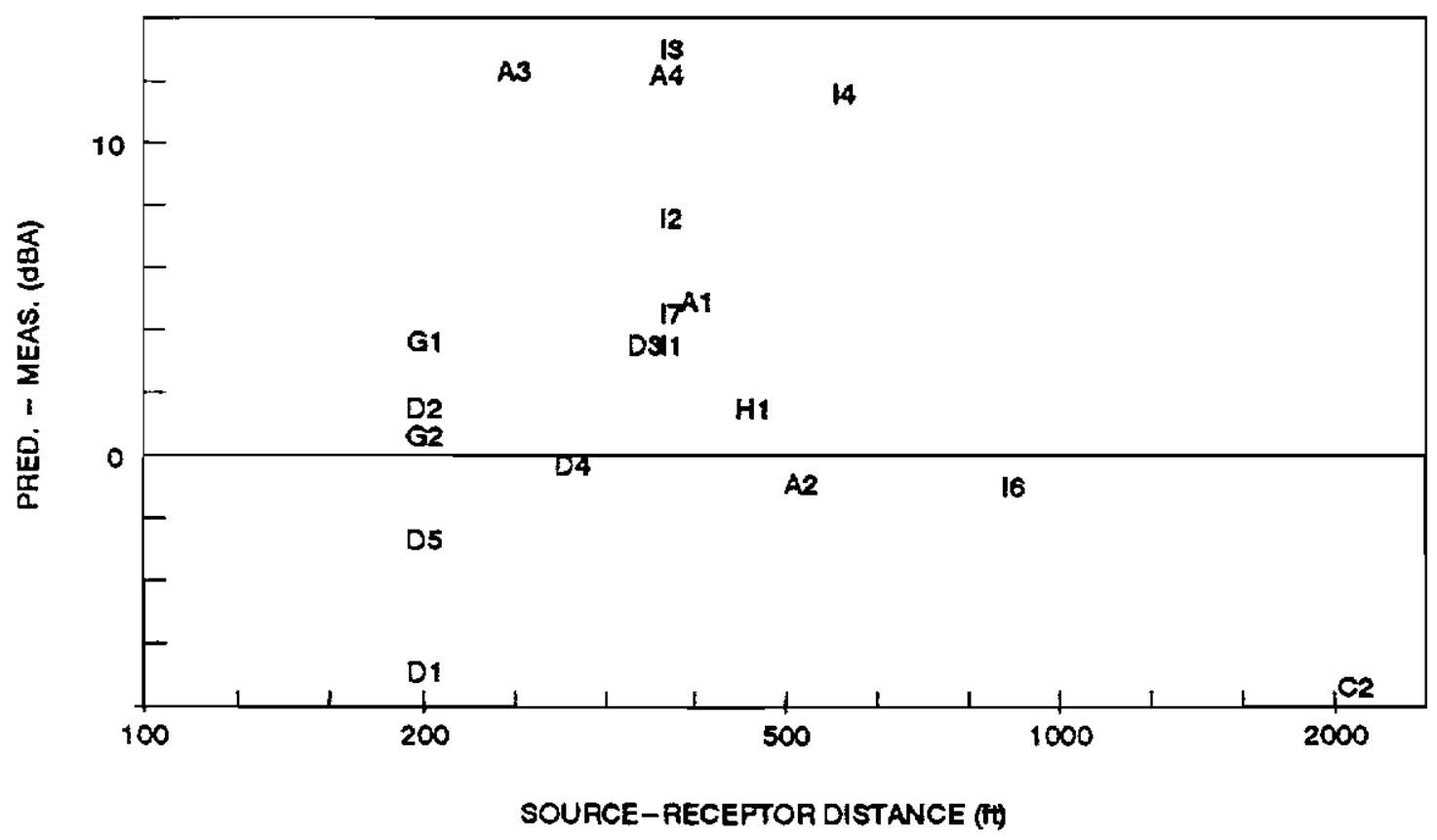

FIGURE 2 Primary-machine-observed sound-level prediction accuracy, for receptors spanning distances of 61 to $640 \mathrm{~m}(200$ to $2,100 \mathrm{ft})$.

\section{DESIGN SOUND LEVELS}

Uncertainty exists in all engineering analyses-whether the prediction of noise from a processing-plant site or the stresses in an aircraft wing or bridge structure. For this reason. the concept of a safety margin has long been applied to contain the risks of nonconservative predictions. For aircraft wings and bridge structures, the consequences of failure are severe: thus. high cost for high confidence is justified. In the case of noise prediction. failure (i.e.. underestimation) rarely incurs immediate and dire consequences. When noise mitigation is found necessary. it may be retrofitted without irreparable harm (although usually with greater cost).

The verification analysis provides the bases not only to correct for prediction accuracy, but also to include a design margin of safety. As a balance between prediction confidence and cost, use of a 1-standarddeviation margin of safety is recommended as reasonable engineering practice. When this safery margin and the expected accuracy are combined. the "Design Goal Adjustments" (DGA) per Table 7 are obtained. where the predicted sound level plus the adjustment should not exceed the criterion (i.e., $L_{\text {prest }}+\mathrm{DGA}=L_{\mathrm{Cm}}$ ).

For some situations, it is useful to evaluate the predictions as $L_{\text {Pred }}$ $=L_{\mathrm{Cnt}}-$ DGA. For example. if a jurisdiction limits average sound levels to $55 \mathrm{~dB}(\mathrm{~A})$ for a land-use zone. then the design goal for the predicted sound levels is $L_{\text {Prec }}=55+1.9 \approx 57 \mathrm{~dB}(\mathrm{~A})$ with respect to the average sound-level limit. If the jurisdiction also limits maximum sound levels (assume Ist percentile sound levels) to $60 \mathrm{~dB}(\mathrm{~A})$, then the design goal for the predicted sound levels is $L_{\text {Pred }}=60-6.7 \approx$ $53 \mathrm{~dB}$ (A) with respect to the "maximum" limit. Because the $L_{1}$ limit

TABLE 7 Prediction Uncertainty, Descriptor, and Design-Goal Adjustments

\begin{tabular}{|c|c|c|c|c|}
\hline $\begin{array}{c}\text { SOUND } \\
\text { LEVEL } \\
\text { DESCRIPTOR } \\
{\left[L_{x}\right]}\end{array}$ & 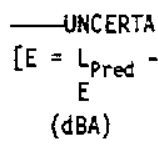 & $\begin{array}{l}\mathrm{L}_{\text {Meas }} I \\
\mathrm{~S}_{\mathrm{E}} \mathrm{I} \\
(\mathrm{dBA})\end{array}$ & $\begin{array}{l}\text { DESCRIPTOR } \\
\text { ADJUSTMENT } \\
{\left[\begin{array}{c}{\left[L_{x}-L_{A P N I}\right.} \\
(d B A)\end{array}\right]}\end{array}$ & $\begin{array}{c}\text { DESIGN GOAL } \\
\text { ADJUSTMENT } \\
{\left[L_{\text {Crit }}-L_{\text {Pred }}\right]} \\
(d B A)\end{array}$ \\
\hline$L_{\text {App }}$ & 3.3 & 6.1 & -- & 2.8 \\
\hline $\mathrm{L}_{\text {eq }}$ & 6.5 & 4.6 & -4.5 & -1.9 \\
\hline$L_{50}$ & 8.1 & 4.3 & -5.6 & -3.8 \\
\hline$L_{10}$ & 3.9 & 4.6 & -1.9 & 0.8 \\
\hline$L_{1}$ & -1.0 & 5.7 & 2.2 & 6.7 \\
\hline
\end{tabular}

* mean differences for 13-16 comparisons; standard deviations, 2.8-4.1 dBA

+ includes one-standard-deviation $\left(S_{E}\right)$ margin of safety, i.e., adjustment is $S_{E}-E$ 


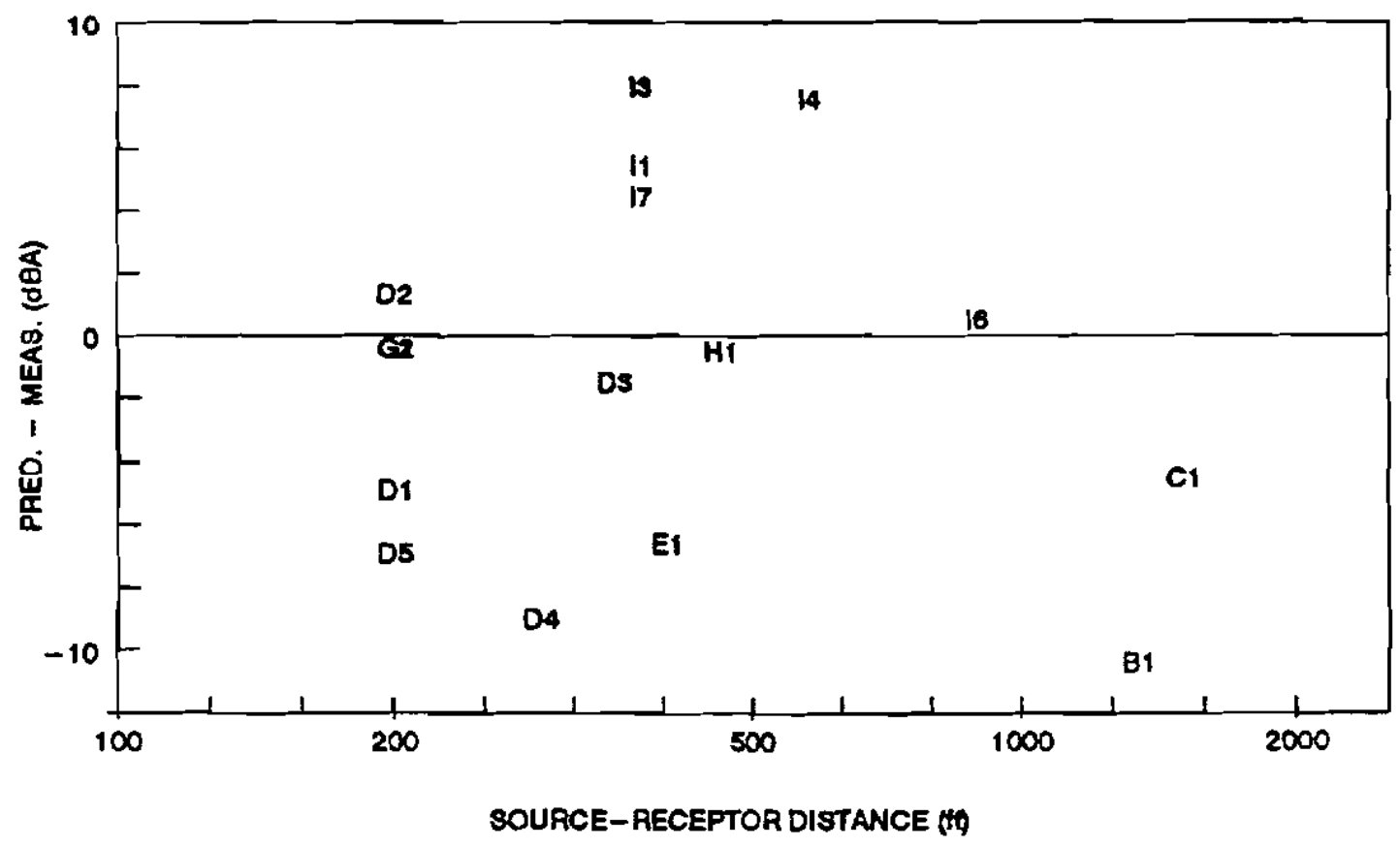

(a)

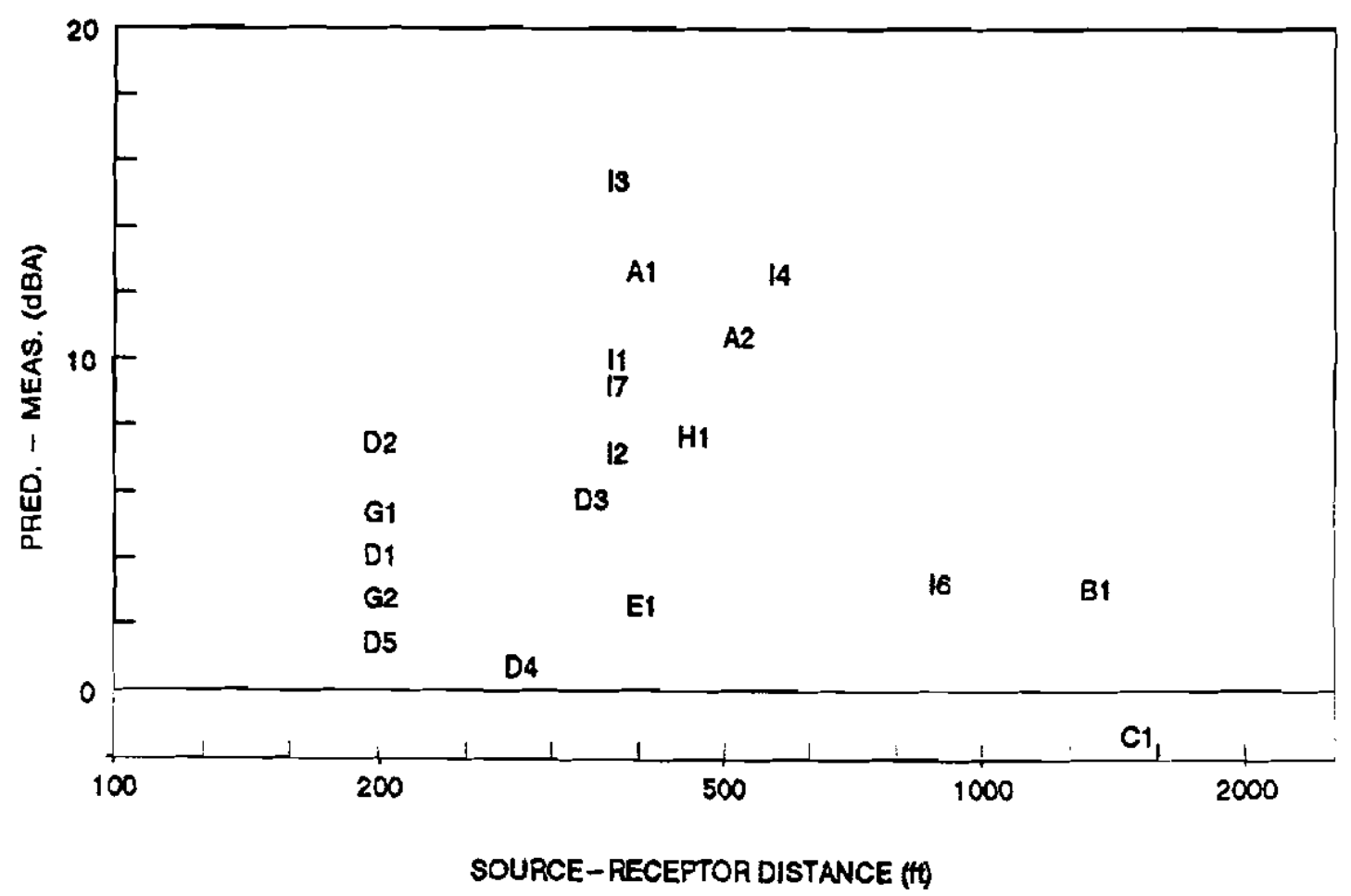

(b)

FIGURE 3 Equipment ensemble and measurement period prediction accuracy, for receptors spanning distances of 61 to $640 \mathrm{~m}[200$ to $2,100 \mathrm{ft}$ : [ $[$ ] equivalent sound levels, (b) 1 st percentile sound leveis. 
is more restrictive than the average limit. it sets the design goal for the site-noise predictions.

\section{CONCLUSIONS}

Several conclusions are drawn from these results. Simplified equipment-noise emission tests are adequate for characterizing noise sources and can provide the basis for receptor-noise computations. Given the irregularity of propagation paths, simple assumptions to represent sound propagation and analyses in temns of overall sound levels are reasonable. Whereas various source-operating conditions may produce widely varying noise emissions, calculations using the maximum-noise operating condition, along with statisrical adjustments for various site noise descriptors, work well, especially with the incorporation of an uncertainty-derived safety margin in design goals.

\section{REFERENCES}

1. Piercy. J. E., T. F. W. Embleton. and L. C. Souherland. Review of Noise Propagation in the Atmosphere. Journal of the ticustical Society of America. Vol. 61. No. 6. June 1977,

2. Barry. T. M. and J. A. Reagan. FHWA Highway Traffic Cioise Prediction Model. Report FHWA-RD-77-108. FHWA. U.S. Department of Transporzation. 1978

3. Maekawa. Z. Noise Reduction by Screens Applied Acoustics. Vol. 1, 1968. pp. 157-173.

Publication of this paper sponsored by Comnittee on Transportation-Reiated Norse and Vibration 